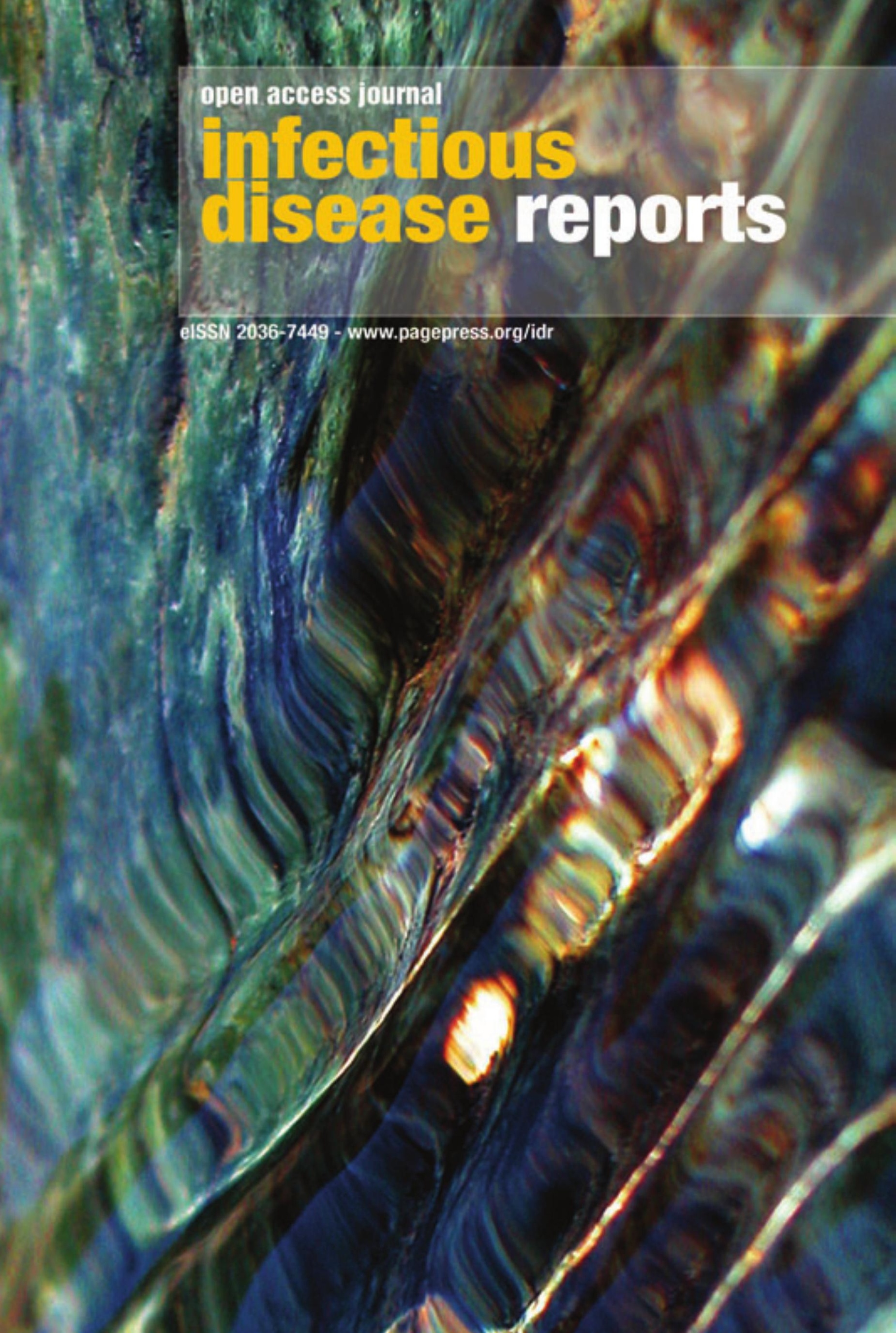




\section{INFECTIOUS DISEASE REPORTS}

is published by PAGEPress Publications.

The journal is completely free online at www.pagepress.org/idir

Publishing costs are offset by a publication fee charged to authors.

For more information

and manuscript submission:

www.pagepress.org/idir

\section{Copyright Information}

All works published in PAGEPress journals are subject to the terms

of the Creative Commons Attribution License

(http:/creativecommons.org/licenses/by-nc/3.0) unless otherwise noted.

Copyright is retained by the authors.

Any non-commercial reuse is permitted if

the original author and source are credited.

\section{Correspondence}

Our publishing offices are located in via Giuseppe Belli 4, 27100 Pavia, Italy. Our telephone number is $\mathbf{+ 3 9 . 0 3 8 2 . 1 7 5 1 7 6 2}$ and our fax number is $\mathbf{+ 3 9 . 0 3 8 2 . 1 7 5 0 4 8 1}$. E-mail: info@pagepress.org

All PAGEPress journals are Open Access. PAGEPress articles are freely available online and deposited in a public archive immediately upon publication. 


\section{INFECTIOUS DISEASE REPORTS}

ISSN 2036-7430 - eISSN 2036-7449

\section{Editor-in-Chief}

David Aronoff, Ann Arbor, MI, USA

\section{Editorial Board}

Mohamed Abd Elmonem Dkhil, Saudi Arabia

Wonder Drake, USA

N. Cary Engleberg, USA

Jeffrey C. Hatcher, USA

Andreas Karas, UK

Vinod Joshi, India

Michele L. Pearson, USA

Nicola Petrosillo, Italy

Nitin K. Saksena, Australia

Joseph D. Schwartzman, USA

Juarez A. Simões Quaresma, Brazil

Sunit K. Singh, India

Vincent B. Young, USA

Jason Weinberg, USA

David P. Wilson, Australia

\section{Editorial Staff}

Nicole Pezzolo, Managing Editor Cristiana Poggi, Production Editor Anne Freckleton, Copy Editor Jeanette Mitchell, Copy Editor Filippo Lossani, Technical Support 


\section{Infectious Disease Reports}

2009; Volume 1

Welcome to Infectious Disease Reports:

a message from the Editor

David M. Aronoff.

Carpal tunnel syndrome and HIV infection.

A case report and literature review

Andrés Reyes-Corcho, Dagnis Barrueta-Reyes, Yadira Bouza-Jimenez,

Blas Clemente Jam-Morales, Yanelka Bouza-Jiménez,

Yarima Lopez-Puig.

Dengue hemorrhagic fever in a peripheral blood stem cell transplant recipient: the first case report

Jirayu Visuthranukul, Udomsak Bunworasate, Panisinee Lawasut,

Chusana Suankratay

Repeated Dientamoeba fragilis infections:

a case report of two families from Sydney, Australia

Damien Stark, Joel Barratt, John Ellis, John Harkness,

Deborah Marriott

Salmonella typhimurium epidural empyema

in an HIV-infected patient

Wissem Hachfi, Foued Bellazreg, Mohamed Ladib, Naoufel Kaabia,

Mabrouk Khalifa, Hedi Krifa, Amel Letaief. 


\title{
Spreading information in science
}

\author{
PAGEPress aims to be a truly international organization \\ by providing access to the scientific literature to anyone, \\ anywhere, by publishing works from every nation, \\ and by engaging a geographically diverse group of scientists \\ in the editorial process.

\begin{abstract}
PAGEPress aims to create a new chapter of the so-called Library of Science using Open Access
\end{abstract}

PAGEPress is a brand of MeditGroup, an Italian media company which has been developing services for the international scientific community since 1992.

PAGEPress is now launching a range of peer-reviewed, open access scholarly journals covering several scientific fields.

All material published by PAGEPress, whether submitted to or created by PAGEPress, is published under an open access license that lets others remix, and build upon your work non-commercially, and although their new works must also acknowledge you and be non-commercial, they don't have to license their derivative works on the same terms.

PAGEPress strives to set the highest standards of excellence in all aspects of its activities, whether this be its journal image, its style of presentation, the quality of the editorial process at every level, the transparency of its operations and procedures, its accessibility to the scientific community and the public, and its educational value.

PAGEPress is committed to a fair and rigorous editorial process. The decision to accept an article for publication will be based purely on scientific quality and importance.

PAGEPress welcomes and actively seeks opportunities to work together with any group (scientific/scholarly societies, physicians, patient advocacy groups, educational organizations) and any publisher who shares our commitment to Open Access and to making scientific information available for the benefit of science and the public good.
PAGEPress Open Access journals are an ideal platform for the publication of your research enabling you to reach the widest available audience of professionals in your field of expertise. Publication in our journals means that your research articles will be available for immediate free access online. PAGEPress shortens the time needed before publication, offers a high quality peer review system and submission to many online Open Access directories.

Many researchers are choosing to publish in our Open Access journals thanks to the promise of a quick and discerning peer review, immediate free access to your research, the wide range and prestige of our journals, and much much more. Find out more about why many authors choose to publish with us and consider the advantages to be gained.

All research articles published by PAGEPress are subject to a rigorous peer review system. The Editorial Board of each journal is responsible for the form the peer review process will take. Find out more about the peer review policy for each of our journals secure in the knowledge that every article you submit to a

PAGEPress journal will enjoy a speedy and efficient appraisal.

PAGEPress allows and encourages authors to deposit both their pre- and post-prints in open-access institutional archives or repositories. The primary benefit of self-archiving is reaching a larger audience which enhances the visibility and impact of your research. 


\section{Welcome to Infectious Disease Reports: a message from the Editor}

\section{David M. Aronoff}

Division of Infectious Diseases, Department of Internal Medicine, The University of Michigan Health System, Ann Arbor, MI, USA

Welcome to the new online-only, international, Open Access, peer-reviewed journal, Infectious Disease Reports (IDR). It is a profound honor to lead this new journal, and I would like to share with you my vision for IDR and take this opportunity to encourage you to submit your work for peer review. It is a great challenge to define the scope of a new infectious disease journal given the wide breadth of our rapidly-evolving field. Infectious diseases present both ongoing and emerging threats to human health. In addition to the "usual offenders" that reap havoc on global human populations (e.g., malaria, tuberculosis, pneumonia, HIV/AIDS), we regularly find ourselves challenged by unexpected and emerging infectious disease threats. Recent examples include epidemics/pandemics (e.g., H1N1 influenza, Ebola virus, severe acute respiratory syndrome [SARS]); large-scale outbreaks (e.g., Vibrio cholerae, Escherichia coli, Norovirus, other food-borne infections); antimicrobial and antiviral resistance (e.g., extremely drugresistant tuberculosis [XDR-TB], extendedspectrum beta lactamases, antiviral-resistant HIV); and the transcontinental migration/ importation of infectious agents (e.g., monkeypox, West Nile virus, tuberculosis). In this light, the scope of IDR must be broad, to cap- ture and address the rapidly-shifting global challenges faced by the ID community.

The editorial staff at IDR are committed to insuring that manuscripts published here are novel and meet the needs of a diverse audience. Because our field of infectious diseases includes longstanding problems and emerging threats, IDR seeks to publish manuscripts including:

- expert reviews (both invited and unsolicited) that identify current gaps in our knowledge

- original investigations (including basic science, translational and clinical research)

- case series and case reports, which are often the heralds of emerging ID threats.

In addition, IDR encourages the submission of manuscripts that include the use of novel research tools or address our field from a multidisciplinary perspective. Examples of innovative areas that could be targeted for reviews or original manuscripts include studies of human microbial ecology or the use of systems biology, nanotechnology, and metagenomics to address problems in infectious diseases. I envision manuscripts in IDR addressing the following areas (in no particular order):

- international health/pandemics

- microbial pathogenesis and host immunology

- virology

- bacteriology

- mycology

- parasitology

- vaccinology

- epidemiology

- diagnostics (including novel, rapid, and field-based methods)

- treatment.
Correspondence: David M. Aronoff, 4618-C Med. Sci. Bldg. II, 1150 W. Medical Center Dr., Ann Arbor, MI 48109-5623, USA

E-mail: daronoff@umich.edu

Received for publication: 8 September 2009 . Accepted for publication: 8 September 2009 .

This work is licensed under a Creative Commons Attribution 3.0 License (by-nc 3.0)

CC Copyright D.M. Aronoff 2009

Infectious Disease Reports 2009; 1:e1

doi:10.4081/idr.2009.e1

The Open Access, online-only era is upon us. An exciting consequence of online access is the ease with which we can reach out across geographical, cultural, and political barriers to communicate about the latest infectious disease problems and solutions. In many international regions, Open Access is seen as a natural, financially sustainable alternative to standard publishing. PAGEPress, the publisher of $I D R$, is committed to offering a publication platform to developing and developed countries alike.

We have populated the Editorial Board of $I D R$ with a balance of young (emerging) and established infectious disease experts to ensure that our manuscripts are current, of wide interest, address controversies and unanswered questions, and help stimulate further advances in the field. I strongly encourage you to submit your work to IDR. I look forward to seeing $I D R$ grow into a major infectious disease journal that makes robust contributions to controlling the global threat of human infection. 


\section{Carpal tunnel syndrome and HIV infection. A case report and literature review}

\author{
Andrés Reyes-Corcho, 'Dagnis Barrueta- \\ Reyes, ${ }^{2}$ Yadira Bouza-Jiménez, ${ }^{3}$ \\ Blas C. Jam-Morales, ${ }^{4}$ \\ Yanelka Bouza-Jiménez, ${ }^{5}$ \\ Yarima Lopez-Puig ${ }^{6}$ \\ 'Former Chief of the Department of \\ Infectious Diseases. Gustavo Aldereguía \\ Lima Teaching Hospital, Cienfuegos, \\ Cuba; ${ }^{2}$ Neurosurgery Service. Gustavo \\ Aldereguía Lima Teaching Hospital, \\ Cienfuegos, Cuba; ${ }^{3}$ Emergency Care \\ Department. Paquito González Cueto \\ Teaching Hospital, Cienfuegos, Cuba; \\ ${ }^{4}$ Department of Infectious Diseases. \\ Gustavo Aldereguía Lima Teaching \\ Hospital, Cienfuegos, Cuba; ${ }^{5}$ Department \\ of Internal Medicine, Gustavo Aldereguía \\ Lima Teaching Hospital, Cienfuegos, \\ Cuba; ${ }^{\circ}$ Neurosurgery Resident, \\ Neurosurgery Service. Gustavo \\ Aldereguía Lima Teaching Hospital, \\ Cienfuegos, Cuba
}

\section{Abstract}

The first clinical case of carpal tunnel syndrome (CTS) in Cuban HIV-infected patient was described, and the scientific literature indexed in: PUBMED/MEDLINE, LILACS and BIREME were revised. The case presented was a male with HIV infection without preceding opportunistic illnesses, CD4+ T cell count over 200 cells $/ \mathrm{mm}^{3}$ and clinical symptoms of pain, tingling and numbness in the right hand and wrist for three months. The electrophysiological study was compatible with CTS. The pharmacological treatment did not modify the symptoms and the patient received specific surgical treatment with absolute resolution of symptoms. CTS is a compressive neuropathy that can occur in HIV-positive individuals with as similar frequency as in the general population. The association between HIV infection and CTS is scarcely described in the medical scientific literature and probably does not represent a different phenomenon from what happens in the HIV-negative population. Nevertheless, its clinical recognition among other neurological and muscle-skeletal manifestations in HIV-infected patients is important.

\section{Introduction}

Carpal tunnel syndrome (CTS) is a compartment compressive neuropathy of the median nerve in the wrist. The disease has a prolonged course of pain, paresthesia and functional limitation of the upper extremities in the median nerve distribution. Although CTS has been described as one of the most common peripheral neuropathy, the prevalence in the general population differs from the published studies. ${ }^{1}$ A recent study in Holland reported a crude annual incidence of 1.8 cases per 1000 people. ${ }^{2}$ The most extensive research conducted in Switzerland identified a prevalence of $3.8 \%$ by clinical diagnosis and $2.7 \%$ after considering clinical and electrophysiological findings. ${ }^{1}$ Although the syndrome is often an occupational disease predominantly in women, ${ }^{3}$ several factors such as obesity, hypothyroidism, and connective tissue diseases have been related in the genesis of this medical condition. ${ }^{4,5}$

Peripheral neuropathic manifestations often occur in HIV-positive individuals. The cytopathic effect of HIV, certain opportunistic infections involving the peripheral nervous system, and in recent years, the neurotoxicity of some antiretroviral drugs, have been raised among the possible etiologies. ${ }^{5}$ However, the association between CTS and HIV infection has only been reported anecdotally related with Mycobacterium avium complex co-infection. ${ }^{6}$ After the advent of highly active antiretroviral therapy (HAART), few case reports have been published and postulated a possible association of the CTS with the prolonged use of viral protease inhibitors (PIs). ${ }^{5}$ This communication describes the first case of CTS in a Cuban HIV-infected patient.

\section{Case Report}

The patient was a 35-year-old male with sexual acquired HIV infection since December 2004, so far without suffering from AIDS-related opportunistic diseases or other co-morbidities. He was admitted in the Department of Infectious Diseases at Gustavo Aldereguía Lima Teaching Hospital, concerning pain, numbness and tingling in the right upper limb, primarily in the hand and wrist for three months. Few weeks before the admission symptoms progressively worsened, were more frequent at night, and were not alleviated with analgesics and non-steroidal anti-inflammatory drugs (NSAIDs). The patient had no treatment for HIV infection.

There was no history of trauma, skin lesions suggestive of herpes zoster, fever or headache. There were no clinical stigmata of hypothyroidism or rheumatic disease. The patient had
Correspondence: Yadira Bouza-Jiménez, Lombart St. 9, Cumanayagua, Cienfuegos, Cuba. ZC: 57 600. E-mail: anitasrb2000@yahoo.es

Key words: human immunodeficiency virus (HIV) infection; carpal tunnel syndrome; clinical diagnosis; treatments.

Contribution: AR-C, clinical diagnosis, patients' follow-up, assessment of HIV infection evolution, review of the manuscript; DB-R, surgical treatment, preparation of the manuscript; YB-J, review of the manuscript; BCJ-M, preparation of the manuscript; YB-J, preparation of the manuscript; YL-P, preparation of the manuscript.

Conflict of interest: the authors report no conflicts of interest.

Received for publication: 11 July 2009. Accepted for publication: 22 September 2009.

This work is licensed under a Creative Commons Attribution 3.0 License (by-nc 3.0).

(c) Copyright A. Reyes-Corcho et al., 2009

Infectious Disease Reports 2009; 1:e2

doi:10.4081/idr2009.e2

no occupational risk for CTS. Physical examination identified painful hyperesthesia in the rights wrist and forearm at the distribution of the median nerve, and positives Tinel (paresthesia painful strike to the distal wrist crease) and Phalen (paresthesia in the distribution of the median nerve to the dorsal flexion of the wrist at $90^{\circ}$ to 60 seconds) signs. There were no signs of muscle atrophy or loss of tactile discrimination at the thenar eminence of the right hand. The Body Mass Index (BMI) was 23.8.

The blood analysis showed no abnormalities, the sedimentation rate (ESR) was 15 $\mathrm{mm} / \mathrm{h}$; C-reactive protein and rheumatoid factor were negative. There were no alterations in blood chemistry, including normal values of total CPK, LDH, TSH and FT4. His absolute $\mathrm{CD}^{+}{ }^{+} \mathrm{T}$ cell count was 234 cells $/ \mathrm{mm}^{3}$ and the Plasma Viral Load for HIV was 320 copies/mL. The radiographs of the cervical spine and cranium-spinal joint showed no bone abnormalities. The electrophysiological study of upper limb was considered diagnostic of CTS according to the criteria of Kimura et al. and Portillo et al. (Table 1). ${ }^{7,8}$

\section{Discussion}

The prevalence of CTS in HIV positive individuals does not appear to be higher than in the general population. A Spanish study con- 
ducted by Asensio et al. identified CTS in the $0.9 \%$ of HIV-infected patients. ${ }^{9}$ In the United States, Márquez et al. described this medical condition in the $2.6 \%$ of 75 HIV-positive cases with HAART. ${ }^{10}$ The $63 \%$ of adults with CTS attended in a rheumatic diseases clinic in Lusaka, Zambia had HIV infection. ${ }^{11}$

Several factors and clinical situations have arisen in the genesis of this syndrome (Table 2). Many of them, as some occupational activities, hypothyroidism, rheumatoid arthritis and obesity, are also mentioned in HIV-infected individuals. ${ }^{5,9,12}$ Clinical observations published by Sclar and Manfredi related CTS with the HAART-associated metabolic syndrome particularly to PIs. ${ }^{5,13}$ One explanation for this observation has been the myxedematous accumulation in the carpal tunnel and secondary compression of the median nerve..$^{12}$ Asensio et al. found no relation between the lipodystrophy secondary to PIs and CTS. ${ }^{9}$ The patient did not have the above diseases and has not been receiving HAART when the CTS was diagnosed, therefore, as happened with other published cases, it would be hasty to establish association with HIV infection or HAART. There is a communication of CTS in HIV-positive individual treated with recombinant growth hormone. ${ }^{14}$

The patient had the typical clinical characteristics of the disease limited to the right hand and wrist, the characteristic pain with nocturnal worsening and paresthesias, which were partially relieved with the flapping of the hands (Flick sign). The electrophysiological study identified prolongation of motor and sensory distal latencies of the right median nerve and increase of the sensory conduction velocity exceeding $41.9 \mathrm{~m} / \mathrm{s}$, confirming the diagnosis. It was also found prolongation of the distal motor latency of left median nerve. The electrophysiological involvement of both median nerves in the absence of bilateral clinical manifestations has been described in several communications. ${ }^{1,7,8}$

The revised series highlights the high sensitivity of symptoms and clinical signs, over $90 \% .{ }^{12}$ Some authors have raised the lack of a gold test for the diagnosis of CTS, while others argue that the combination of clinical findings with electrophysiological abnormalities is sufficient for the diagnosis. ${ }^{15}$ Although the clinical symptoms are not necessarily related with the severity of neurological impairment, the presence of atrophy is correlated with the most severe and significant alterations in the electro-physiological studies, indicating axonomyelinic damage. ${ }^{7}$ Other clinical aspects such as Tinel and Phalen signs appear earlier and in the presence of suggestive electrophysiological findings help to the early diagnosis of the syndrome. ${ }^{7,15}$

Several studies included CTS among HIVassociated rheumatopathies and described

Table 1. Electrophysiological study findings.

\begin{tabular}{lcccc} 
Measurements & $\begin{array}{c}\text { Right } \\
\text { median nerve }\end{array}$ & $\begin{array}{c}\text { Right cubital } \\
\text { nerve }\end{array}$ & $\begin{array}{c}\text { Left median } \\
\text { nerve }\end{array}$ & $\begin{array}{c}\text { Left cubital } \\
\text { nerve }\end{array}$ \\
PML (mseg) & 8.8 & 7,4 & 8,0 & 7,0 \\
DML (mseg) & 5.0 & 2.4 & 4.8 & 2.8 \\
\hline PMA (mseg) & 9.9 & 6.2 & 9.2 & 6.3 \\
DMA (mseg) & 7.3 & 6.0 & 8.9 & 6.0 \\
\hline DSL (mseg) & 4.4 & 2.0 & 3.6 & 2.1 \\
MCV m/s & 68.21 & 69.36 & 62.50 & 63.29 \\
\hline SCV m/s & 44.62 & 41.2 & 41.8 & 41.4 \\
\hline
\end{tabular}

L: latency, A: amplitude, M: motor, S: sensorial, CV: nerve conduction velocity, P: proximal, D: distal.

Table 2. Diseases, clinical conditions and socio-occupational factors associated with carpal tunnel syndrome.

\section{Diseases, clinical conditions and socio-occupational factors}

I Endocrine-metabolic

Diabetes mellitus

Hypothyroidism

Acromegaly

Obesity

HAART-related metabolic syndrome

II Rheumatologic and muscle-skeletal disorders

Rheumatoid arthritis

Carpal and metacarpal osteoarthritis

Colles fracture

Luxation of semilunar bone

Cumulative trauma of the wrist

Gout

III Chronic infection

Tuberculosis and other mycobacterial infections HIV/AIDS

IV Chronic and inflammatory disorders

Chronic renal failure and hemodialysis

Amyloidosis

$\checkmark$ Occupational factors

Office work

Manufacturing

Construction

Healthcare personnel, nurses, home services and others

VI- Sports, sport climbing

VII Other states and conditions

Pregnancy

Menopause

Smoking

Genetic factors

Hormone therapy

VIII CTS idiopathic (15\%)

alterations of the ESR and C-reactive protein. ${ }^{10,12}$ However, these findings were not identified in our patient, and it could depend on the few inflammatory components of the disease in the presented case. CTS associated to rheumatoid arthritis, amyloidosis, chronic renal failure, and infectious diseases like tuberculosis, might be related with acceleration of the ESR and increasing of inflammation markers.
The patient received many treatments with NSAIDs, which only slightly modified the symptoms. It was coordinated with the Neurosurgery Staff and surgery was performed. Surgical treatment is indicated for moderate and severe stages of the disease. It can be performed by conventional or endoscopic techniques, in both cases it consist in decompressing the median nerve through the opening of the flexor retinaculum. ${ }^{12}$ There is 
agreement among studies regarding the efficacy of surgery in the remission of clinical manifestations of CTS..$^{12,16}$ The patient had successful recovery and when this report was wrote (one year after surgery), he was absolutely asymptomatic and with no functional limitation of the hand.

\section{Conclusions}

CTS can be diagnosed in HIV-positive patients with as similar frequency as in the general population. Based on current evidence, there is a controversial association among HIV infection, HAART and CTS, and probably does not represent a different phenomenon from what happens in HIV-negative population. However, the clinical recognition of the syndrome between the numerous neurological and muscle-skeletal disorders related with HIV infection and AIDS is important.

\section{References}

1. Atroshi I, Gummesson C, Johnsson R, et al. Prevalence of carpal tunnel syndrome in a general population. JAMA. 1999;282:153-8.

2. Bongers FJ, Schellevis FG, van den Bosch
WJ, van der Zee J. Carpal tunnel syndrome in general practice (1987 and 2001): incidence and the role of occupational and non-occupational factors. Br J Gen Pract 2007; 57:36-9.

3. Atroshi I, Gummesson C, Ornstein E, et al. Carpal tunnel syndrome and keyboard use at work: a population-based study. Arthritis Rheum 2007; 56:3620-5.

4. Atroshi I, Gummesson C, Johnsson R, et al. Prevalence for clinically proved carpal tunnel syndrome is 4 percent. Lakartidningen 2000;97:1668-70.

5. Sclar Gary. Carpal tunnel syndrome in HIV1 patients: a metabolic consequence of protease inhibitor use? AIDS 2000; 14:3368.

6. Woolley I, Faragher M, Spelmand D. Association between HIV distal symmetric polyneuropathy and Mycobacterium avium complex infection. J Neurol Neurosurg Psychiatry 1997;63:557.

7. Kimura J. Electrodiagnosis in diseases of nerves and muscle: principle and practice. 2nd ed. Philadelphia: FA Davis Company; 1989; p.501-4.

8. Portillo R, Salazar M, Huertas MA. Síndrome del túnel del carpo: correlación clínica y neurofisiológica. An Fac Med Lima 2004;65:247-54.

9. Asensio 0, Caso JA, Rojas R. Carpal tunnel syndrome in HIV patients? AIDS 2002;
16:948-50.

10. Marquez J, Restrepo CS, Candia L, et al. Human immunodeficiency virus-associated rheumatic disorders in the HAART era. J Rheumatol 2004; 31:741-6.

11. Njobvu P, McGill P. Soft tissue rheumatic lesions and HIV infection in Zambians. J Rheumatol 2006; 33:2493-7.

12. Lima AL, Zumiotti AV, Camanho GL, et al. Osteoarticular complications related to HIV infection and highly active antiretroviral therapy. Braz J Infect Dis 2007; 11(4):426-9.

13. Manfredi R, Calza L, Chiodo F. Carpal tunnel syndrome in HIV-infected patients treated with highly active: other case reports. Rheumatol Int 2001;21:81-3.

14. Cominelli S, Raguso CA, Karsegard L, et al. Weight-losing HIV-infected patients on recombinant human growth hormone for 12 wk: a national study. Nutrition 2002; 18:583-6.

15. Rempel D, Evanoff B, Amadio PC, et al. Consensus criteria for the classification of carpal tunnel syndrome in epidemiologic studies. Am J Public Health 1998;88:144751.

16. Gerritsen AA, Uitdehaag BM, van Geldere D, et al. Systematic review of randomized clinical trials of surgical treatment for carpal tunnel syndrome. Br J Surg 2001; 88:1285-95. 


\section{Dengue hemorrhagic fever in a peripheral blood stem cell transplant recipient: the first case report}

\author{
Jirayu Visuthranukul,,2 \\ Udomsak Bunworasate, ${ }^{3}$ \\ Panisinee Lawasut, ${ }^{3}$ \\ Chusana Suankratay' \\ 'Division of Infectious Diseases, \\ Department of Medicine, Faculty of \\ Medicine, Chulalongkorn University, \\ Bangkok, Thailand; 'Division of Infectious \\ Diseases, Department of Medicine, Police \\ General Hospital, Bangkok, Thailand; \\ ${ }^{3}$ Division of Hematology, Department of \\ Medicine, Faculty of Medicine, \\ Chulalongkorn University, Bangkok, \\ Thailand
}

\section{Abstract}

Dengue infection, a mosquito-borne infectious disease in tropical and subtropical areas, has recently become an emerging global disease. The clinical course of dengue infection may be unfavorable in immunocompromised patients. In this report, we present a 16-year old female patient with acute myeloid leukemia who received allogeneic peripheral blood stem cell transplant five months prior to presentation. She was hospitalized at King Chulalongkorn Memorial Hospital, Bangkok, Thailand, due to fever, headache, and myalgia for one day. During hospitalization, she developed capillary leakage syndrome and progressive thrombocytopenia. A diagnosis of dengue hemorrhagic fever was made and confirmed by positive dengue serology and polymerase chain reaction testing. She made a full recovery 14 days after hospitalization. Our case possibly acquired dengue virus from infected mosquitoes while visiting her relatives four days before her present illness. In conclusion, this is the first reported case of dengue hemorrhagic fever in a peripheral blood stem cell transplant recipient. In addition, we review all previous reports of dengue infection in organ transplant recipients.

\section{Introduction}

Dengue infection is an acute infectious disease caused by four dengue virus serotypes 1 , 2,3 , and $4 .{ }^{1.7}$ The principal vector is Aedes aegypti, a mosquito with worldwide distribution in many tropical and subtropical areas.
The clinical spectrum of dengue infection varies from asymptomatic to severe disease. All serotypes produce a similar clinical illness characterized by acute fever, headache, generalized myalgia, nausea, and vomiting, and induce a life-long immunity that is specific to the infecting serotype. ${ }^{7,8}$ A small proportion of infected individuals may develop a severe form of disease, dengue hemorrhagic fever (DHF), characterized by fever, thrombocytopenia, hemorrhagic manifestations, and excessive capillary leakage probably leading to dengue shock syndrome (DSS) and death. ${ }^{1.7}$ The clinical course of dengue infection may be unfavorable in immunocompromised patients. Bone marrow transplant recipients have an impaired cell-mediated immunity, placing them at increased risk of infections. We report a case of DHF in a peripheral blood stem cell recipient, and review all previous reports of dengue infection in organ transplant recipients.

\section{Case Report}

A 16-year old female was hospitalized at King Chulalongkorn Memorial Hospital, Bangkok, Thailand, due to a high-grade fever without chills, bitemporal headache, generalized myalgia, and nausea one day prior to admission. She had returned four days before from visiting her relatives at Chon Buri, East Thailand. The patient had been diagnosed with acute myeloid leukemia (type M4) 14 months prior to the present illness when she noted acute fever, petechial rash, and bleeding of her gums and nose. She received induction and a consolidation course of chemotherapy. Allogeneic peripheral blood stem cell transplantation was performed five months before the present illness. She was in complete remission when last seen one month prior to her present illness. Complete blood count (CBC) showed hematocrit of $28 \%$, white blood cell count of $4.89 \times 10^{9} / \mathrm{L}$ (neutrophil $46 \%$, lymphocytes $40 \%$, and monocytes $6.9 \%$ ), and platelet count of $186 \times 10^{9} / \mathrm{L}$. Her current medications include cyclosporine, acyclovir, and cotrimoxazole. Physical examination revealed an acutely ill patient with body temperature of $39.7^{\circ} \mathrm{C}$ and bilateral anterior cervical lymphadenopathy. CBC showed hematocrit of $33 \%$, white blood cell count of $6.3 \times 10^{9} / \mathrm{L}$ (neutrophil $80 \%$, lymphocyte $8 \%$, atypical lymphocyte $5 \%$, and monocyte $7 \%$ ), and platelet count of $120 \times 10^{9} / \mathrm{L}$. Three days after hospitalization, a relapse of acute myeloid leukemia could not be excluded, and hence bone marrow was examined and revealed decreased cellularity, adequate megakaryocytes, increased histiocytes and eosinophils, consistent with reactive marrow to probable certain infection.
Correspondence: Chusana Suankratay, Division of Infectious Diseases, Department of Medicine, Chulalongkorn University, Bangkok 10330, Thailand. E-mail: chusana.s@chula.ac.th

Key words: dengue, dengue hemorrhagic fever, stem cell transplantation, bone marrow transplantation.

Conflict of interest: the authors reported no potential conflicts of interests.

Received for publication: 23 September 2009. Revision received: 26 October 2009. Accepted for publication: 27 0ctober 2009.

This work is licensed under a Creative Commons Attribution 3.0 License (by-nc 3.0).

○Copyright J. Visuthranukul et al., 2009 Infectious Disease Reports 2009; 1:e3 doi:10.4081/idr.2009.e3

Eight days after hospitalization, she noted petechial rash over both her legs, and physical examination revealed moderate hepatomegaly and right pleural effusion. CBC showed hematocrit of $38 \%$, white blood cell count of $8.84 \times 10^{\%} / \mathrm{L}$ (neutrophil $79 \%$, lymphocyte $5 \%$, atypical lymphocyte $13 \%$, and monocyte $3 \%$ ), and platelet count of $16 \times 10^{9} / \mathrm{L}$. DHF was suspected, and later confirmed by enzyme-linked immunoassorbant assay ${ }^{9}$ and reverse transcriptase-polymerase chain reaction (PCR) testing. ${ }^{10}$ A diagnosis of primary dengue infection was made with dengue IgM of more than $40 \mathrm{U}$ and $\mathrm{IgM} / \mathrm{IgG}$ ratio of or more than 1.8:1 (dengue IgM rose from 86.65 to $121.03 \mathrm{U}$, and IgG rose from 49.18 to $134.01 \mathrm{U}$ ). Twelve days after hospitalization, she developed convalescent rash over her extremities. She eventually made a full recovery, and was discharged 14 days after hospitalization.

\section{Discussion}

This is the first reported case of dengue hemorrhagic fever in a peripheral blood stem cell transplant recipient. Our case had primary dengue infection, and possibly acquired dengue virus from infected mosquitoes while visiting her relatives at Chon Buri. Clinical manifestations of dengue infection in immunocompromised patients are usually similar to those noted in immunocompetent individuals. However, some patients experienced a longer duration (more than seven days) of illness than that in healthy individuals (4-7 days). ${ }^{1-3}$ A 23-year old renal transplant recipient developed dengue hemorrhagic fever which lasted for 19 days. ${ }^{11}$ Our patient also had a 12-day course of dengue hemorrhagic fever. 
In addition, an unusual presentation of dengue infection has been reported..$^{12,13}$ A 25 -year old patient with aplastic anemia with dengue infection developed polyserositis while he underwent conditioning for allogeneic stem cell transplant from his brother. ${ }^{12}$ Another case of unusual dengue infection was described in a renal transplant recipient who developed acute colitis one week after returning from Southeast Asia. ${ }^{13}$

Furthermore, a transmission of dengue infection from an organ transplant donor during transplantation has been reported. ${ }^{11,14}$ One case of possible transmission of dengue infection from a living donor to a renal transplant recipient was described. ${ }^{11}$ This patient developed acute fever five days after receiving a kidney transplantation from his mother who later had a positive PCR test in the blood for dengue virus serotype 1 . Another case of dengue infection transmission was described in a bone marrow transplant recipient during a dengue epidemic in Puerto Rico in 1994..$^{14}$ A 6-year old recipient developed an acute febrile episode four days after a transplant, and eventually died. Dengue serotype 4 was isolated from the blood and post-mortem tissues. The donor developed a dengue-like illness two days after a transplant. A diagnosis of dengue infection was confirmed by a positive dengue IgM from ELISA testing.

There are a few studies on the histopathology of bone marrow in dengue infection, and most of them are from post-mortem cases with severe dengue infection. ${ }^{15-17}$ Diffuse hypocellularity with and without hemophagocytosis is always described in bone marrow of patients with dengue hemorrhagic fever. In our case, examination of bone marrow revealed diffuse hypocellularity despite being performed early in the course of dengue infection.

This is the first report describing dengue hemorrhagic fever in a peripheral blood stem cell recipient. A high index of suspicion of dengue infection should be given to every transplant patient living or returning from endemic areas who presents with an acute fever in association with viral syndrome.

\section{References}

1. Rigau-Pérez JG, Clark GG, Gubler DJ, et al. Dengue and dengue haemorrhagic fever. Lancet 1998;352:971-7.

2. Jelinek T. Dengue fever in international travelers. Clin Infect Dis 2000;31:144-7.

3. Mairuhu AT, Mac Gillavry MR, Setiati TE, et al. Is clinical outcome of dengue-virus infections influenced by coagulation and fibrinolysis? A critical review of the evidence. Lancet Infect Dis 2003;3:33-41.

4. Gibbons RV, Vaughn DW. Dengue: an escalating problem. Br Med J 2002;324:1563-6.

5. Guzmán MG, Kourí G. Dengue: an update. Lancet Infect Dis 2002;2:33-42.

6. Wilder-Smith A, Schwartz E. Dengue in travelers. N Engl J Med 2005;353:924-32.

7. Halstead SB. Dengue. Lancet 2007;370: 1644-52.

8. Lee MS, Hwang KP, Chen TC, et al. Clinical characteristics of dengue and dengue hemorrhagic fever in a medical center of southern Taiwan during the 2002 epidemic. J Microbiol Immunol Infect 2006;39: 121-9.

9. Vaughn DW, Green S, Kalayanarooj S, et al.
Dengue in the early febrile phase: viremia and antibody responses. J Infect Dis 1997; 176:322-30.

10. Lanciotti RS, Calisher CH, Gubler DJ, et al. Rapid detection and typing of dengue viruses from clinical samples by using reverse transcriptase-polymerase chain reaction. J Clin Microbiol 1992;30:545-51.

11. Tan FL, Loh DL, Prabhakaran K, et al. Dengue haemorrhagic fever after living donor renal transplantation. Nephrol Dial Transplant 2005;20:447-8.

12. Ullah K, Ahmed P, Raza S, et al. Allogeneic stem cell transplantation in hematological disorders: single center experience from Pakistan. Transplant Proc 2007;39:334757.

13. Park SB, Ryu SY, Jin KB, et al. Acute colitis associated with dengue fever in a renal transplant recipient. Transplant Proc 2008; 40:2431-2.

14. Rigau-Pérez JG, Vorndam AV, Clark GG. The dengue and dengue hemorrhagic fever epidemic in Puerto Rico, 1994-1995. Am J Trop Med Hyg 2001;64,67-74.

15. Peres LC, Saggioro FP, Dias LB Jr, et al. Infectious diseases in paediatric pathology: experience from a developing country. Pathology 2008;40:161-75.

16. Rothwell SW, Putnak R, La Russa VF. Dengue-2 virus infection of human bone marrow: characterization of dengue-2 antigen-positive stromal cells. Am J Trop Med Hyg 1996;54:503-10.

17. Jain D, Singh T. Dengue virus related hemophagocytosis: a rare case report. Hematology 2008;13:286-8. 


\section{Repeated Dientamoeba fragilis infections: a case report of two families from Sydney, Australia}

Damien Stark, ${ }^{1,2}$ Joel Barratt,, John Ellis, ${ }^{1}$ John Harkness, ${ }^{1,2}$ Deborah Marriott ${ }^{1,2}$

'Division of Microbiology, SydPath, St. Vincent's Hospital, Sydney, Australia; 2Department of Medical and Molecular Biosciences, University of Technology Sydney, Broadway, Australia

\section{Abstract}

We report cases of two unrelated families who both presented with recurrent Dientamoeba fragilis infections. Subsequent antimicrobial therapy resulted in the clearance of $D$. fragilis and total resolution of gastrointestinal symptoms in both families. This report highlights the potentially recurrent nature of $D$. fragilis infections and the need for laboratories to routinely test for this organism.

\section{Introduction}

Dientamoeba fragilis is a pathogenic amoeboid protozoan parasite that is closely related to the Trichomonads. The parasite has been shown to cause gastrointestinal disease in a wide range of patient groups, has a world-wide distribution and is often more prevalent than Giardia., ${ }^{1,2}$ Chronic symptoms have been reported previously in patients presenting with $D$. fragilis infection. ${ }^{3}$ One study found that $32 \%$ of $D$. fragilis infected patients had persistent diarrhoea and associated symptoms of greater than 2 weeks duration. ${ }^{4}$ We report two separate cases of repeated $D$. fragilis infection in family members sharing the same residence who by genotyping were determined to be infected by different strains of $D$. fragilis.

\section{Case Report}

\section{Case \#1}

A 41-year-old male (patient \#1) presented with a history of chronic diarrhoea and weight loss over a period of several months. A faecal sample was collected and routine bacteriological cultures were performed along with investigation for parasites. Due to the chronic nature of the condition no virology was performed on the samples given the acute, selflimiting nature of viral gastroenteritis. No bacterial pathogens were detected by culture.
Parasitology testing was performed on faecal samples fixed in sodium acetate acetic acid formalin and permanently stained using a modified iron-haematoxylin stain as previously described. ${ }^{4}$ Diagnosis of $D$. fragilis infection was made based on the finding of binucleate, pleomorphic, granular, amoeboid cells, typical of $D$. fragilis in the initial stained smear. ${ }^{4}$ The patient was treated with metronidazole, symptoms improved, and on follow up examination of stool sample $(\mathrm{n}=1)$ no parasites were detected, indicating that the infection was successfully cleared. Several months after the initial presentation and subsequent successful treatment of the $D$. fragilis infection the patient presented again with gastrointestinal complaints including a variation in bowel motions from watery diarrhoea to unformed faecal motions. Stool samples were resubmitted again and underwent routine bacteriological culture, and permanent staining of fixed faecal smears for the identification of protozoan parasites. In addition a portion of stool sample underwent DNA extraction and PCR using specific primers targeting the SSUrDNA of $D$. fragilis as previously described. ${ }^{5}$ No bacterial pathogens were identified, while microscopic analysis of the stained smears detected $D$. fragilis trophozoites and the $D$. fragilis PCR was also positive for $D$. fragilis DNA. After the diagnosis of dientamoebiasis was made the patient was treated with doxycycline and iodoquinol. The patients symptoms resolved after treatment and subsequent stool samples submitted post treatment $(\mathrm{n}=2)$ were negative for Dientamoeba by both microscopy and PCR.

At the same time the patient's mother, a 75year-old female (patient \#2), who cohabited at the same residence as her son also presented with a history of gastrointestinal symptoms including bouts of diarrhoea and unformed stools, faecal urgency, digestive problems and food intolerance. Microbiological analysis was undertaken on stool specimens including microbial cultures, parasitology testing, and $D$. fragilis specific PCR. Bacterial cultures were negative and the permanent stained faecal smears of the mother's stool specimen demonstrated the presence of Blastocystis hominis. No Dientamoeba trophozoites were detected by microscopy. However a positive $D$. fragilis PCR result was obtained from the mother's stool demonstrating the presence of Dientamoeba DNA. Sequencing of the PCR products from mother and son was undertaken as previously described. $^{5}$ The Dientamoeba-specific PCR product obtained from the stool of the patient's mother was sequenced and found to have identical SSU rDNA sequence as that obtained from her son. ${ }^{5}$ Given that the SSU rRNA gene displays insufficient variability to be used as a definitive epidemiological marker the previously described $D$. fragilis typing method of Cprofiling was undertaken on both samples. ${ }^{6}$
Correspondence: Damien Stark, Department of Microbiology, St.Vincent's Hospital, Darlinghurst 2010, NSW, Australia. E-mail: dstark@stvincents.com.au

Key words: Dientamoeba fragilis.

Contribution: DS, main author, molecular analysis, microbiological and laboratory testing; JB, molecular analysis, microbiological and laboratory testing testing article input, proof reading; JE, molecular analysis, article input, proof reading; $\mathrm{JH}$, clinical input, patient follow up article input, proof reading; DM, clinical input and treatment of patients, article input, proof reading.

Received for publication: 7 September 2009.

Revision received: 26 October 2009.

Accepted for publication: 28 0ctober 2009.

This work is licensed under a Creative Commons Attribution 3.0 License (by-nc 3.0).

CCCopyright D. Stark et al., 2009

Infectious Disease Reports 2009; 1:e4

doi:10.4081/idr.2009.e4

Both $D$. fragilis samples yielded different Cprofiles indicating the strains were not genotypically identical (Figure 1). Patient \#2 was treated with secnidazole, nitazoxanide and doxycycline, which resulted in total parasitological clearance and resolution of the patient's symptoms. Follow-up samples collected after treatment and again some 3 months later failed to detect any $D$. fragilis either by microscopy or by molecular methods. As En terobius vermicularis has been proposed by some as a possible vector for transmission of $D$. fragilis, multiple sticky-tape tests were collected from both $D$. fragilis infected patients. A total of 6 tape tests were collected and examined; no E. vermicularis ova were detected.

\section{Case \#2}

A family comprising of the father (58 years of age), mother (49 years of age), son (13 years of age) and daughter (10 years of age) presented to their local general practitioner with gastrointestinal complaints after a holiday to Tasmania. The gastrointestinal symptoms included diarrhoea, abdominal pain and bloating. One month after the holiday in April 2008, all four patients submitted stool samples for routine bacteriological cultures along with investigation for parasites. No bacterial pathogens were isolated. However $D$. fragilis was detected by microscopy of permanently stained faecal smears as previously described, in three out of the four patients (father and both children). Both children also presented with a peripheral eosinophilia. In May all four patients were treated with metronidazole and 
symptoms resolved. No follow-up stool samples were collected to check for clearance of parasite. Four months later in September, three of the family (father, son and daughter), presented with gastrointestinal symptoms, faecal samples were resubmitted and $D$. fragilis was detected by permanent stained microscopy in all three patients with the father also having the non-pathogenic flagellate Chilomastix mesnili present. All three patients were subsequently treated with paramomycin for 10 days. Follow-up stool samples were collected one month after cessation of treatment and no $D$. fragilis was detected by microscopy. Five months later the family once again presented with gastrointestinal complaints and microbiological analysis of faecal samples were performed. Dientamoeba fragilis was detected in 2/4 family members (father and son) by microscopy of permanent stained smears,. Faecal samples were then collected from all members of the family and an RT-PCR was performed as described. ${ }^{7}$ The PCR assay detected $D$. fragilis in all family members, including the two members who were microscopy negative for $D$. fragilis only 5 days earlier. In order to fingerprint the $D$. fragilis strains, C-profiling was used to determine if the infection was from a single source. Only two samples, from the father and son were able to be fingerprinted using this technique and both strains were shown to be genotypically different (Figure 1). Treatment was initiated for all family members (paramomycin for 10 days). All family members reported resolution of symptoms and follow-up molecular analysis of stool samples one month later detected no $D$. fragilis DNA. Follow-up two months later showed that the family was still symptom and parasite free.

\section{Discussion}

Dientamoeba fragilis is a protozoan parasite that has recently emerged as an important cause of parasitic gastrointestinal disease..$^{1,4}$ Recent studies have shown the organism to be widespread with relatively high prevalence rates ranging from $8.9 \%$ to $16.8 \%$ in developed regions of the world. ${ }^{8-10}$ Gastrointestinal symptoms attributed to Dientamoeba infection most commonly include diarrhoea and abdominal pain, with chronic infection often reported., ${ }^{4,11,12}$ Numerous studies have shown antimicrobial therapy targeting and eliminating $D$. fragilis will result in marked clinical improvement for patients suffering from dientamoebiasis., ${ }^{3,12,13}$

All patients from both families presented with a repeated $D$. fragilis infection over prolonged periods of time. Bacterial etiological agents were excluded by routine testing. Dientamoeba was detected by either microscopy or PCR (or both) in the patients' sam- ples. The PCR detected $D$. fragilis infections that would have been subsequently missed if microscopy only had been used. Molecular testing has been shown to provide excellent sensitivity and specificity when compared to microscopy for the detection of $D$. fragilis and provides an additional diagnostic tool for laboratories with this capability. ${ }^{7}$ The symptoms described in all patients included a variation in bowel motions with bouts of diarrhoea, unformed stool samples and faecal urgency along with stomach pain and cramps.

In case \#1, patient \#1 had a previous $D$. fragilis infection which initially seemed to respond to therapy; however the patient presented again several months later. Whether the latter infection was a new infection from a different source, a reinfection from the same source or even treatment failure is unknown. Samples from the first episode of infection were not collected for molecular analysis. As it was possible that the reinfection was due to selection of resistant $D$. fragilis strains and subsequent treatment failure both patients were treated with combination therapy to eradicate the organism. One patient was treated with doxycline and iodoquinol while the other secnidazole, nitazoxanide and doxycycline. Both patients responded to treatment with eradication of the organism and resolution of symptoms. The patient who was treated with secnidazole, nitazoxanide and doxycycline did complain of side effects from the antimicrobial agents.

The patients from case \#2 had gastrointestinal complaints for over a year and even though treatment was given on several occasions to family members, $D$. fragilis and gastrointestinal complaints returned. As some members of the family had resolution of symptoms and clearance of $D$. fragilis from stools after treatment it must be assumed that the patients were getting re-infected. After treatment with metronidazole after the initial $D$. fragilis "outbreak" amongst the family, no follow-up stool samples were examined for clearance of the parasite. Subsequent symptomatic presentations occurred only in the father and children. When all family members were treated at the same time, the symptoms and parasites were cleared, and to-date, several months later, the family remains symptom and parasite free.

Molecular testing, using C-profiling, was performed and both $D$. fragilis isolates from case \#1 (patients \#1 and \#2) were shown to be different, indicating infection from a different source. C-profiling on case \#2 samples also showed the strains were not identical. C-profiling is a method that has been used for the molecular epidemiological typing of $D$. fragilis that targets the internal transcribed spacer regions (ITS). ${ }^{6}$ The ITS regions have been used extensively for phylogenetic analyses and as a molecular epidemiological marker of other parasites and in particular members of the Trichomonadidae. ${ }^{6}$ The method detects intragenomic variation in the $D$. fragilis ITS region which leads from direct amplification of samples to sequencing fluorograms that are too complex to interpret, due to multiple ITS sequence variants in a single isolate. However, since the ITS regions of $D$. fragilis are extremely AT rich and the C-content is low by deleting fluorogram peaks representing the other nucleotides (A, T and $\mathrm{G}$ ), it is possible to analyse $\mathrm{C}$ nucleotide residues producing chromatographs that are reproducible and easy to interpret. Bart et al. clearly demonstrated that the intragenomic variation of the ITS regions of $D$. fragilis can be used as a molecular epidemiological marker. ${ }^{6}$ In both cases the $D$. fragilis strains were shown to be genotypically different, so it must be assumed that both patients obtained the infection from a different source.

Sticky-tape tests collected from all patients were negative for $E$. vermicularis and so it must be assumed that infection occurred by direct transmission. Recent studies have not shown a role for $E$. vermicularis in transmis-

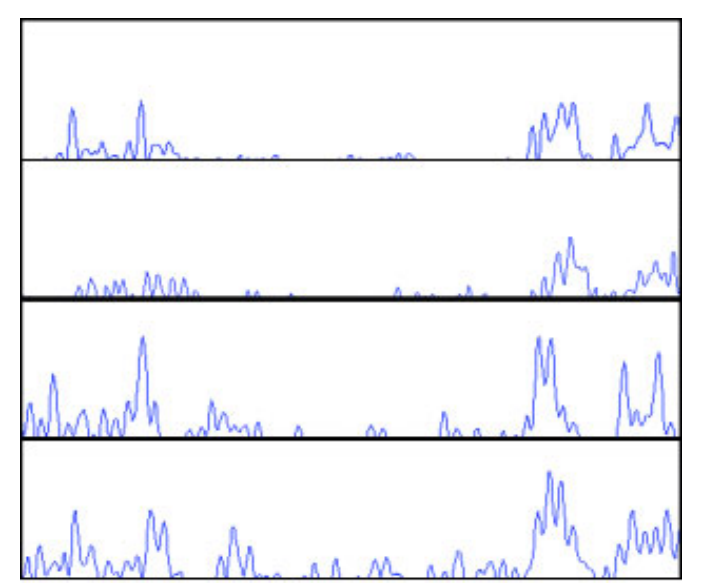

Figure 1. C-profiles from Case 1 and Case 2. From top to bottom Case 1 patient 1 , patient 2, Case 2 father, Case 2 son. 


\section{sion of $D$. fragilis.}

This report highlights the repeated nature of some $D$. fragilis infections. Given that the organism can be treated effectively with a number of antimicrobial agents, all laboratories should provide a parasitological service capable of detecting this organism. All family members or those living in the same residence should be screened for $D$. fragilis as asymptomatic carriers may provide an ongoing source of infection.

\section{References}

1. Vandenberg 0, Peek R, Souayah H, et al. Clinical and microbiological features of dientamoebiasis in patients suspected of suffering from a parasitic gastrointestinal illness: a comparison of Dientamoeba fragilis and Giardia lamblia infections. Int J Infect Dis 2006;10:255-61.

2. Crotti D, D'Annibale ML, Fonzo G, et al. Dientamoeba fragilis is more prevalent than Giardia duodenalis in children and adults attending a day care centre in Central Italy. Parasite 2005;12:165-70.
3. Stark DJ, Beebe N, Marriott D, et al. Dientamoebiasis: clinical importance and recent advances. Trends Parasitol 2006; 22:92-6.

4. Stark D, Beebe N, Marriott D, et al. Prospective study of the prevalence, genotyping, and clinical relevance of Dientamoeba fragilis infections in an Australian population. J Clin Microbiol 2005;43:271823.

5. Stark D, Beebe N, Marriott D, et al. Detection of Dientamoeba fragilis in fresh stool specimens using PCR. Int J Parasitol 2005;35:57-62.

6. Bart A, van der Heijden HM, Greve S, et al. Intragenomic variation in the internal transcribed spacer 1 region of Dientamoeba fragilis as a molecular epidemiological marker. J Clin Microbiol 2008;46: 3270-5.

7. Stark D, Beebe N, Marriott D, et al. Evaluation of three diagnostic methods, including real-time PCR, for detection of Dientamoeba fragilis in stool specimens. J Clin Microbiol 2006;44:232-5.

8. Stensvold CR, Arendrup MC, Molbak K, Nielsen HV. The prevalence of Dientamoeba fragilis in patients with suspected enteroparasitic disease in a metropolitan area in Denmark. Clin Microbiol Infect 2007;13:839-42.

9. Schuster H, Jackson BM. Prevalence of Dientamoeba fragilis amongst patients consulting complimentary medicine practitioners in the British Isles. J Clin Pathol 2008 0ct 24.

10. Rayan HZ, Ismail OA, El Gayar EK. Prevalence and clinical features of Dientamoeba fragilis infections in patients suspected to have intestinal parasitic infection. J Egypt Soc Parasitol 2007;37:599608.

11. Ito R, Sakagami J, Kataoka K, et al. Chronic diarrhea and protein-losing gastroenteropathy caused by Dientamoeba fragilis. J Gastroenterol 2004;39:1117-9.

12. Johnson EH, Windsor JJ, Clark CG. Emerging from obscurity: biological, clinical, and diagnostic aspects of Dientamoeba fragilis. Clin Microbiol Rev 2004; 17:553-70.

13. Vandenberg O, Souayah H, Mouchet F, et al. Treatment of Dientamoeba fragilis infection with paromomycin. Pediatr Infect Dis J 2007;26:88-90. 


\section{Salmonella typhimurium epidural empyema in an HIV-infected patient}

\author{
Wissem Hachfi, ${ }^{1}$ Foued Bellazreg,' \\ Mohamed Ladib, ${ }^{2}$ Naoufel Kaabia, ${ }^{1}$ \\ Mabrouk Khalifa, ${ }^{1}$ Hedi Krifa, ${ }^{2}$ \\ Amel Letaief ${ }^{1}$
}

'Department of Infectious Diseases, and Internal Medicine, Farhat Hached University Hospital; ${ }^{2}$ Department of Neurosurgery, Sahloul University Hospital, Sousse, Tunisia

\section{Abstract}

Salmonella focal intracranial infections are reported rarely. They tend to occur in immunocompromised patients. We present here a case of Salmonella typhimurium epidural empyema, with osteomyelitis of the adjacent frontal bone, in a 37-year-old human immunodeficiency virus positive man who presented with a three-day history of headache, fever, and sweats. He was treated successfully with antibiotics and surgical drainage.

\section{Introduction}

Non-typhoidal salmonella (NTS) infection is a common occurrence among human immunodeficiency virus (HIV) infected patients, and salmonella bacteremia is a frequent finding. The estimated incidence of salmonellosis among patients with acquired immunodeficiency syndrome (AIDS) has been 20- to 100 fold more than that among the general population. ${ }^{1}$ Before the era of AIDS, central nervous system (CNS) localization of NTS infection was reported rarely and meningitis was the most common location, described more frequently in children., ${ }^{2,3}$ Salmonella focal intra cranial infections are unusual in HIV infected patients. We report a case of an HIV patient with a Salmonella typhimurium infection presenting as epidural empyema, with adjacent osteomyelitis of the frontal bone.

\section{Case Report}

A 37-year-old HIV positive man presented at our department on December 10, 2007 with a three-day history of headache, fever, and sweats. Physical examination revealed a Glasgow coma score of $15 / 15$, a temperature of $38.2^{\circ} \mathrm{C}$, a blood pressure of $110 / 70 \mathrm{~mm} \mathrm{Hg}$, a pulse rate of 90 beats/min, and a respiratory rate of 20 breaths/min. No neurological deficit was detected. HIV infection was diagnosed 10 years ago, and antiretroviral therapy (zidovudine-didanosine-lopinavir/ritonavir) had been started in October 2007, when he had esophageal candidiasis with a CD4 cell count of $12 / \mathrm{mm}^{3}(3 \%)$ and an HIV viral load of 110,000 RNA copies/mL.

The laboratory results showed low hemoglobin $(11.1 \mathrm{~g} / \mathrm{dL})$, normal WBC count $\left(6100 / \mathrm{mm}^{3}\right.$ with 4500 neutrophils), and normal platelets $\left(349,000 / \mathrm{mm}^{3}\right)$. The prothrombin time was normal (75\%), as were the values of glucose, creatinine, and electrolytes. Absolute CD4 cell count was $71 / \mathrm{mm}^{3}(9 \%)$. HIV viral load was not performed. On lumbar puncture the cerebrospinal fluid was normal. The chest X-ray was unremarkable. A contrasted computed tomography scan (CT) (Figure 1) and magnetic resonance imaging (MRI) (Figure 2) of the head revealed epidural empyema in the left frontal region, associated with adjacent osteolytic lesions in the frontal bone. There were no signs of brain herniation.

The patient was treated initially with par-
Correspondence: Wissem Hachfi, Unit of Infectious Diseases, Farhat Hached Hospital, 4000 Sousse, Tunisia. E-mail: hachfi_wissem@hotmail.com

Key words: Salmonella typhimurium, epidural empyema, human immunodeficiency virus.

Conflict of interest: the authors report no conflict of interests.

Received for publication: 6 August 2009.

Revision received: 1 November 2009.

Accepted for publication: 4 November 2009.

This work is licensed under a Creative Commons Attribution 3.0 License (by-nc 3.0).

(C) Copyright W. Hachfi et al., 2009

Licensee PAGEPress, Italy

Infectious Disease Reports 2009; 1:e5

doi:10.4081/idr.2009.e5

enteral cefotaxime (12 $\mathrm{g}$ daily) combined with metronidazole (1500 mg daily). Antiretroviral therapy was continued. After 48 hours of antibiotic therapy, fever resolved but the
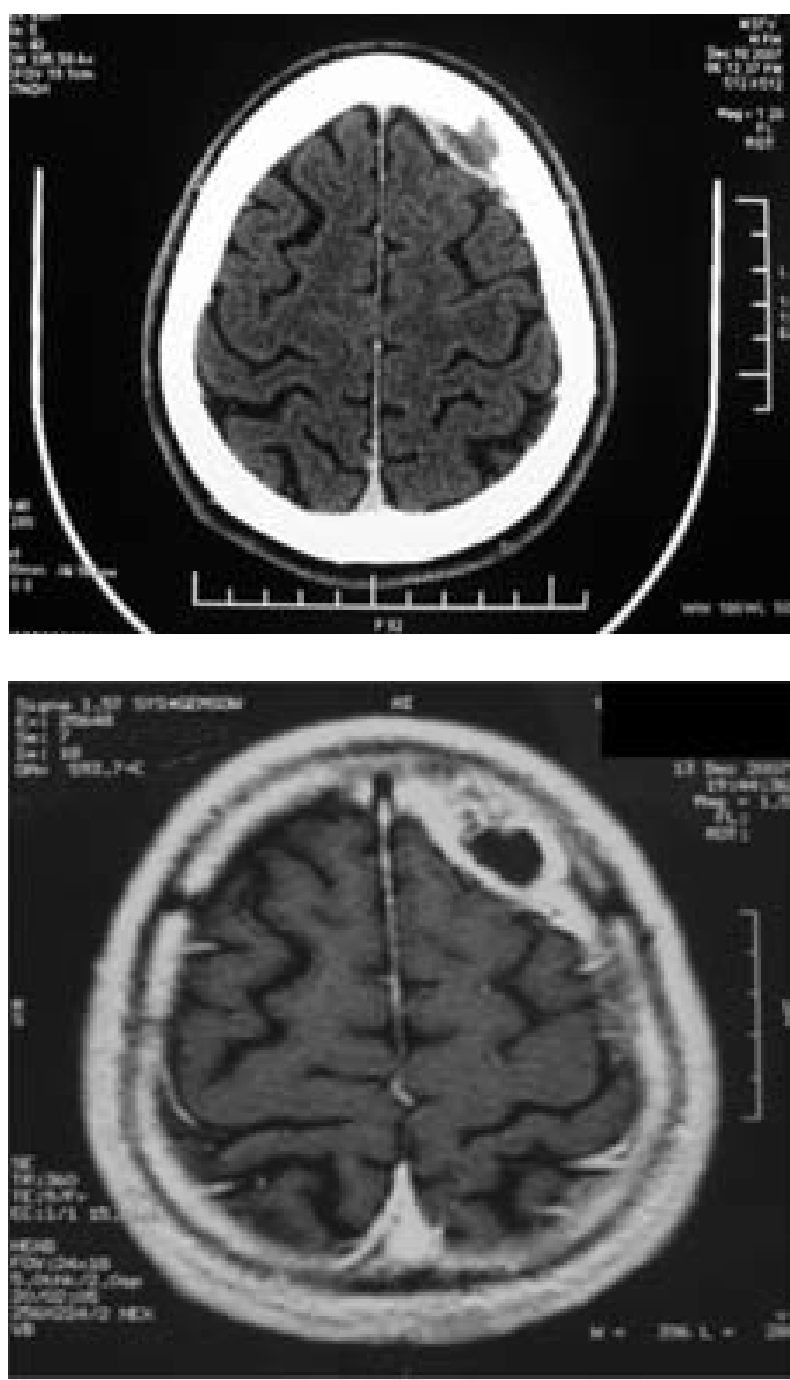

Figure 1. Computed tomography scan of the head showing a $4 \times 1.5-\mathrm{cm}$ left epidural lentiform hypodensity with an adjacent frontal bone defect.
Figure 2. Enhanced T1-weighted magnetic resonance image showing a 5-cm epidural collection with adjacent osteolytic lesions in the left frontal area. 
patient complained of persistant headache. A craniotomy was performed on December 14, producing epidural purulent fluid that was drained. Pus culture yielded a pure growth of a gram-negative bacillus, which was identified as Salmonella typhimurium. A disk diffusion susceptibility test showed the isolate to be susceptible to cefotaxime, ciprofloxacin, and choramphenicol, but resistant to amoxicillin and cotrimoxazole. The antibiotic therapy was changed to ciprofloxacin per os (1000 mg daily). Within two days following the drainage of the fluid collection, the headache subsided. Blood cultures showed no growth after seven days of incubation. Stool culture was not performed. The patient was discharged without any neurological complications. Ciprofloxacin was continued for a period of 12 weeks. A repeat CT scan of the head performed at the end of antibiotic therapy showed the resolution of the epidural empyema (Figure 3). At nine months of follow-up, the patient remained clinically very well. Viral load was of $<25$ RNA copies/mL and CD4 cell count was $198 / \mathrm{mm}^{3}$ (12\%).

\section{Discussion}

The incidence of NTS infection among patients with AIDS exceeds that among the general population. ${ }^{1}$ Frequently salmonellosis in this population is complicated by bacteremia, especially in patients with CD4 counts of $<100 / \mathrm{mm}^{3}{ }^{4}$ However, suppurative complications, particularly those affecting the CNS, have been reported rarely. ${ }^{1}$ NTS meningitis is the most common location of CNS salmonella infection, but remains rare. ${ }^{5}$ Either brain abscess, subdural empyema, or epidural empyema mostly occurs as a complication of salmonella meningitis, but may be an isolated infection.${ }^{6,7}$ Our patient had epidural empyema without meningitis. S. enteritidis and S. typhimurium are the most frequently encountered serotypes associated with salmonella CNS infections. $^{8}$

NTS are food-borne pathogens that primarily cause gastroenteritis, then can reach the bloodstream via the lymphatics, especially in immunocompromised persons. ${ }^{8}$ However, not all individuals with invasive NTS infections have concurrent diarrhea or isolation of the bacteria from the stool. ${ }^{9}$ In a Spanish study, only $34 \%$ of AIDS patients with NTS bacteremia had diarrhea, and salmonella were isolated from the stools in only $4 \%{ }^{9}$ Sarria $e t$ $a l$., in their study of 11 cases of $S$. enteritidis brain abscesses, found antecedent gastroenteritis in only four patients. ${ }^{6}$ Neither intestinal infection nor salmonella bacteremia had been detected in our patient. However, the possibility of transient hematogenous spread of $S$.

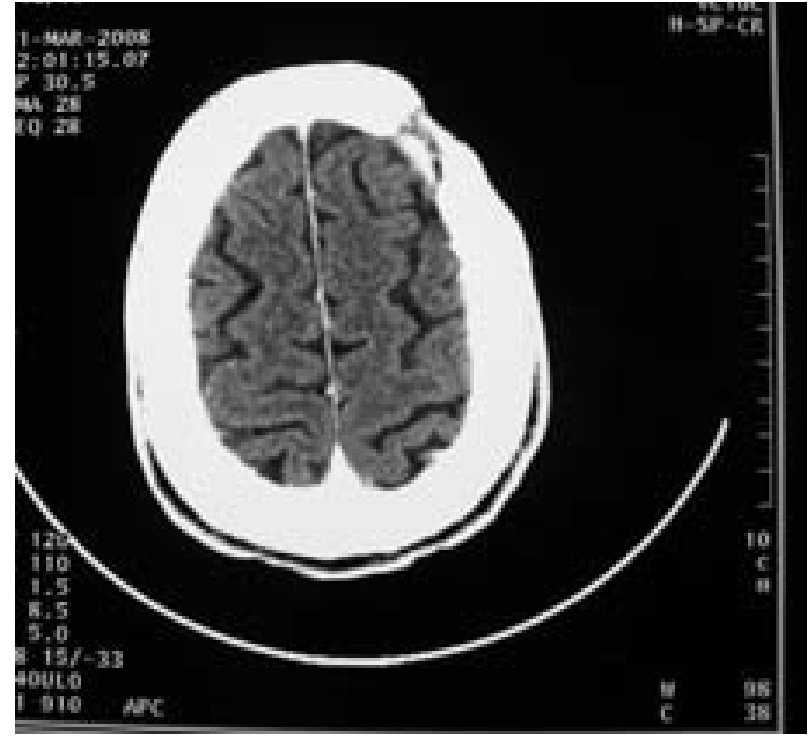

Figure 3. Computed tomography scan of the head performed at the end of antibiotic therapy showing the removal of the epidural empyema.

typhimurium from a pre-existing asymptomatic intestinal infection could not be eliminated.

Although NTS localized infection has not been reported in the literature as a possible manifestation of immune restitution syndrome, we think this supposition could be advanced for our patient. In fact we observed this infection two months after the beginning of antiretroviral therapy, concomitant with an increase of CD4 count. However, our hypothesis lacked the HIV viral load decrease parameter, which was not available when this NTS infection was diagnosed.

Clinical symptoms associated with epidural empyema are nonspecific: headache, fever, seizures, decreased level of consciousness, focal neurological deficit. In our patient, these symptoms were limited to headache and fever. Consequently the diagnosis often is unsuspected or delayed. Therefore early imaging studies, namely CT scan and MRI of the head, are required to make a prompt diagnosis. ${ }^{6}$

Our patient had skull osteomyelitis complicating the epidural empyema. Salmonella skull osteomylitis is extremely rare. It has been noted in two patients with salmonella brain abscess before the era of AIDS..$^{10,11}$ More recently Mastroianni et al. reported a case of frontal salmonella osteomyelitis without intracranial complications in an HIV patient, ${ }^{12}$ and Aliaga et al. reported a case of salmonella subdural and epidural cerebral empyema with concomitant osteomyelitis of the frontal bone in an HIV patient. ${ }^{13}$ In addition salmonella osteomyelitis associated with epidural infection was described in patients with sickle cell disease. ${ }^{14,15}$

High mortality rates have been reported for patients with intracranial infections caused by NTS, and a significant number of survivors developed permanent neurological sequelae. ${ }^{7,16}$ Treatment failure was observed particularly when antibiotics were used alone without surgery. ${ }^{15}$ The use of an adequate antimicrobial regimen combined with early surgical drainage will result in the best probability of cure. ${ }^{7,17}$ The most reliable choices appear to be third-generation cephalosporins and fluoroquinolones because of their high activity against most salmonella strains with high brain tissue and CSF concentrations. Either chloramphenicol or cotrimoxazole could be used as an alternative drug if there is a contraindication to cephalosporins and quinolones. ${ }^{16}$ The recommended duration of treatment is at least four weeks in meningitis and at least six weeks in brain abscess or empyema. ${ }^{16,17}$ Our patient received prompt antimicrobial therapy and surgical drainage, and the duration of antibiotic therapy was prolonged to 12 weeks because he had skull osteomyelitis. He was cured without any sequelae and no relapse was noted at nine months of follow-up.

\section{Conclusions}

Salmonella focal intracranial infections are rare but should be considered by clinicians as a cause of acute CNS disorder in patients with advanced HIV disease. Early diagnosis and treatment are important in order to improve the prognosis of this CNS infection.

\section{References}

1. Sperber SJ, Schleupner CJ. Salmonellosis during infection with human immunodeficiency virus. Rev Infect Dis 1987;9:925-34.

2. Rodriguez RE, Valero V, Watanakunakorn C. Salmonella focal intracranial infections: 
review of the world literature (1884-1984) and report of an unusual case. Rev Infect Dis 1986;8:31-41.

3. Cohen A, Freundlich E, Greif Z. Nontyphoid salmonella septicemia. Harefuah 1987;1112:5-7.

4. Pegues DA, Ohl ME, Miller SI. Salmonella species, including Salmonella typhi. In: Mandell GL, Bennett JE, Dolin R, editors. Principles and practice of infectious diseases. 6th edn. Philadelphia: Elsevier, 2005, pp 2636-50.

5. Leonard MK, Murrow JR, Jurado R, et al. Salmonella meningitis in adults infected with HIV: case report and review of the literature. Am J Med Sci 2002;323:266-8.

6. Sarria JC, Vidal AM, Kimbrough RC. Salmonella enteritidis brain abscess: case report and review. Clin Neurol Neurosurg 2000;102:236-9.

7. Kuruvath S, Basu S, Elwitagala JP, et al. Salmonella enteritidis brain abscess in sickle cell disease patient: case report and review of the literature. Int $\mathrm{J}$ Infect Dis 2008;12:298-302.

8. Hart CA, Beeching NJ, Duerden BI. Infections in AIDS. J Med Microbiol 2000; 49:947-67.

9. Casado JL, Valdezate S, Calderon NE, et al. Zidovudine therapy protects against Salmonella bacteremia recurrence in human immunodeficiency virus-infected patients. J Infect Dis 1999;179:1553-6.

10. Mage J, Martin P. Abcès epidural par ostéomyélite, unique manifestation d'une infection à paratyphique B. Acta Neurol Psychiatr Belg 1958;58:861-7.

11. Suzuki Y, Sugiyama Y, Ishii R, et al. Brain abscess caused by Salmonella typhi: case report. J Neurosurg 1976;45:709-11.

12. Mastroianni CM, Vullo V, Delia S. Cranial Salmonella abscess with parietal bone osteomyelitis in an HIV-infected patient. AIDS 1992;6:749-50.

13. Aliaga L, Mediavilla JD, López de la Osa A, et al. Nontyphoidal salmonella intracranial infections in HIV-Infected Patients. Clin Infect Dis 1997;25:1118-20.

14. Martino AM, Winfield JA. Salmonella osteomyelitis with epidural abscess. A case report with review of osteomyelitis in children with sickle cell anemia. Pediatr Neurosurg 1990;16:321-5.

15. Diebold P, Humbert J, Djientcheu Vde P, et al. Salmonella epidural abscess in sickle cell disease: failure of the nonsurgical treatment. J Natl Med Assoc 2003;95:10958.

16. Owusu-Ofori A, Scheld WM. Treatment of Salmonella meningitis: two case reports and review of the literature. Int $\mathrm{J}$ Infect Dis 2003;7:53-60.

17. Infection in Neurosurgery. The rational use of antibiotics in the treatment of brain abscess. Working Party of the British Society for Antimicrobial Chemotherapy. Br J Neurosurg 2000;14:525-30. 


\section{Instructions to Authors}

To submit a new manuscript:

i) Register as an Author at http://www.pagepress.org/journals/index.php/idr/login We encourage you to register also as a reader and a reviewer at the same time.

To submit a revised version:

i) Login at http://www.pagepress.org/journals/index.php/idr/login

ii) Click on your role as Author

iii) Click on QUEUED FOR REVIEW on the page displayed

iv) Under the heading EDITOR DECISION, upload your revised paper as AUTHOR VERSION using Browse and Upload buttons

v) Use the NOTIFY EDITOR email to inform editors that the revised version has been submitted

Manuscripts must be written in English. The first page must contain: (a) title, name and surname of the authors; (b) names of the institution(s) where the research was carried out; (c) a running title of no more than 50 letters; (d) acknowledgments; (e) the name and full postal address of the author to whom correspondence regarding the manuscript as well as requests for abstracts should be sent; (f) three to five key words. To accelerate communication, phone, fax number and e-mail address of the corresponding author should also be included. The second page should contain: (a) authors' contributions, i.e., information about the contributions of each person named as having participated in the study (http://www.icmje.org/\#author); (b) disclosures about potential conflict of interest. Original Articles should normally be divided into an abstract, introduction, design and methods, results, discussion and references. The abstract should contain about 250 words and must be structured as follows: background, design and methods, results, conclusions. A maximum of 20 authors is permitted, and additional authors should be listed in an ad hoc appendix. Review Articles: no particular format is required for these articles. However, they should have an informative, unstructured abstract of about 250 words. Reviews may also include meta-analyses, guidelines and consensus papers by scientific societies or working groups. These studies must be conducted following proper, widely accepted ad hoc procedures. Brief Reports must provide conclusive findings: preliminary observations or incomplete findings cannot be considered for publication. They should be signed by no more than 10 authors. Brief reports should have a short abstract of no more than 150 words, a text of about 2000 words, a maximum of 3 tables and/or figures (total), and up to 20 references. References should be prepared strictly according to the Vancouver style, which is present in EndNote); for details see the URL: http://www. nlm.nih.gov/bsd/uniform_requirements.html. Where available, URLs for the references should be provided directly within the Word document. References must be numbered consecutively in the order in which they are first cited in the text, and they must be identified in the text by arabic numerals. References to personal communications and unpublished data should be incorporated in the text and not placed under the numbered References.

\section{Peer-review policy}

All manuscript submitted to our journals are critically assessed by external and/or inhouse experts in accordance with the principles of Peer Review (http://www.icmje.org/\#peer), which is fundamental to the scientific publication process and the dissemination of sound science. Each paper is first assigned by the Editors to an appropriate Associate Editor who has knowledge of the field discussed in the manuscript. The first step of manuscript selection takes place entirely inhouse and has two major objectives: a) to establish the article's appropriateness for our journals' readership; b) to define the manuscript's priority ranking relative to other manuscripts under consideration, since the number of papers that the journal receives is much greater than that it can publish. If a manuscript does not receive a sufficiently high priority score to warrant publication, the editors will proceed to a quick rejection. The remaining articles are reviewed by at least two different external referees (second step or classical peer-review).

Manuscripts should be prepared according to the Uniform Requirements established by the International Committee of Medical Journal Editors (http://www.icmje.org/\#prepare).

Authorship. All persons designated as authors should qualify for authorship according to the ICMJE criteria. Each author should have participated sufficiently in the work to take public responsibility for the content. Authorship credit should be based only on substantial contributions to (a) conception and design, or analysis and interpretation of data; and to (b) drafting the article or revising it critically for important intellectual content; and on (c) final approval of the version to be published. These three conditions must all be met. Participation solely in the acquisition of funding or the collection of data does not justi- fy authorship. General supervision of the research group is not sufficient for authorship. Any part of an article critical to its main conclusions must be the responsibility of at least one author. Authors should provide a brief description of their individual contributions.

Obligation to Register Clinical Trials (http://www.icmje.org/\#clin_trials). The ICMJE believes that it is important to foster a comprehensive, publicly available database of clinical trials. The ICMJE defines a clinical trial as any research project that prospectively assigns human subjects to intervention or concurrent comparison or control groups to study the cause-and-effect relationship between a medical intervention and a health outcome. Medical interventions include drugs, surgical procedures, devices, behavioral treatments, process-of-care changes, and the like. Our journals requires, as a condition of consideration for publication, registration in a public trials registry. The journal considers a trial for publication only if it has been registered before the enrollment of the first patient. The journal does not advocate one particular registry, but requires authors to register their trial in a registry that meets several criteria. The registry must be accessible to the public at no charge. It must be open to all prospective registrants and managed by a not-for-profit organization. There must be a mechanism to ensure the validity of the registration data, and the registry should be electronically searchable. An acceptable registry must include a minimum of data elements (http://www.icmje.org/\#clin_trials).

For instance, clinicaltrials.gov (http://www. clinicaltrials.gov), sponsored by the United States National Library of Medicine, meets these requirements.

Protection of Human Subjects and Animals in Research. When reporting experiments on human subjects, authors should indicate whether the procedures followed were in accordance with the ethical standards of the responsible committee on human experimentation (institutional and national) and with the Helsinki Declaration of 1975, (as revised in 2008). In particular, PAGEPress adopts the WAME policy on Ethics in Research (http://www.wame.org). Documented review and approval from a formally constituted review board (Institutional Review Board IRB - or Ethics committee) is required for all studies (prospective or retrospective) involving people, medical records, and human tissues. PAGEPress requires that the authors provide this information on the manuscript's website, and also that they report it explicitly under Design and Methods. When reporting experiments on animals, authors should be asked to indicate whether the institutional and national guide for the care and use of laboratory animals was followed. 


\section{Competing Interests}

Conflict of Interest. According to the International Committee of Medical Journal Editors (http://www.icmje.org/\#conflicts), public trust in the peer review process and the credibility of published articles depend in part on how well conflict of interest is handled during writing, peer review, and editorial decision making. Conflict of interest exists when an author (or the author's institution), reviewer, or editor has financial or personal relationships that inappropriately influence (bias) his or her actions (such relationships are also known as dual commitments, competing interests, or competing loyalties). These relationships vary from those with negligible potential to those with great potential to influence judgment, and not all relationships represent true conflict of interest. The potential for conflict of interest can exist whether or not an individual believes that the relationship affects his or her scientific judgment. Financial relationships (such as employment, consultancies, stock ownership, honoraria, paid expert testimony) are the most easily identifiable conflicts of interest and the most likely to undermine the credibility of the journal, the authors, and of science itself. However, conflicts can occur for other reasons, such as personal relationships, academic competition, and intellectual passion. All participants in the peer review and publication process must disclose all relationships that could be viewed as presenting a potential conflict of interest. Before final acceptance of their manuscript, authors are required to return a declaration on potential conflicts of interest. This ad hoc form is sent to the corresponding author who is responsible for collecting the relevant information and providing a declaration on behalf of all the co- authors. Each author must disclose any of the following potential conflicts concerning the past two years and/or the known future: 1) ownership of stocks, stock options or shares in companies that may reasonably appear to be affected by publication of the paper; 2) employment by any organization that may reasonably appear to be affected by publication of the paper; 3 ) patents or patent applications whose value may reasonably appear to be affected by publication of the paper; 4) consultation fees, paid expert testimony or honoraria from companies that may reasonably appear to be affected by publication of the paper; 5) lecture fees from companies that may reasonably appear to be affected by publication of the paper; 6) institutional research support by commercial firms or private organizations with a proprietary or financial interest in the outcome of the research; 7) any other relationship that could be viewed as creating a potential conflict of interest and/or embarrass the author were it to become publicly known after the paper is published.

\section{Copyright}

PAGEPress has chosen to apply the Creative Commons Attribution License to all manuscripts to be published.

An Open Access Publication is one that meets the following two conditions:

i. The author(s) and copyright holder(s) grant(s) to all users a free, irrevocable, worldwide, perpetual right of access to, and a license to copy, use, distribute, transmit and display the work publicly and to make and distribute derivative works, in any digital medium for any responsible purpose, subject to proper attribution of authorship, as well as the right to make small numbers of printed copies for their personal use.

ii. A complete version of the work and all supplemental materials, including a copy of the permission as stated above, in a suitable standard electronic format is deposited immediately upon initial publication in at least one online repository that is supported by an academic institution, scholarly society, government agency, or other well-established organization that seeks to enable open access, unrestricted distribution, interoperability, and long-term archiving.

Authors who publish with this journal agree to the following terms:

i. authors retain copyright and grant the journal right of first publication with the work simultaneously licensed under a Creative Commons Attribution License that allows others to share the work with an acknowledgement of the work's authorship and initial publication in this journal.

ii. Authors are able to enter into separate, additional contractual arrangements for the non-exclusive distribution of the journal's published version of the work (e.g., post it to an institutional repository or publish it in a book), with an acknowledgement of its initial publication in this journal.

iii. Authors are permitted and encouraged to post their work online (e.g., in institutional repositories or on their website) prior to and during the submission process, as it can lead to productive exchanges, as well as earlier and greater citation of published work.

Updated on February 2010 